\title{
Fine Moving Value in Behavioral Anomalies to Minimize Poverty in Disadvantaged Areas
}

\author{
Taufik Hidayat ${ }^{1}$, Andarula Galu shasti ${ }^{1+}$, Bagus Putu Yudhia Kurniawan ${ }^{1}$ and Retno Sari \\ Mahanani ${ }^{1}$ \\ ${ }^{1}$ Department of Agribusiness Management, State Polytechnic of Jember, East Java, Indonesia
}

\begin{abstract}
Indonesia is a wealthy country with resources, be they human resources or natural resources. However, even if Indonesia is a resource-rich country, it continues to work to solve the problem of poverty. Unfortunately, there is no strategic solution that can alleviate poverty. Deprivation triggers a behavioral anomaly in society, especially in disadvantaged areas. This research aims to determine the effect of community behavior on poverty alleviation in underprivile ged areas. The study is based on a subtle value-moving approach to behavioral irregularities of people in disadvantaged areas. This study is included in a quantitative research with regional populations in Indonesia designated as lagging regions in 2020-2021. The sample of respondentsincluded 110 people from areas/provinces designated as lagging areas. Research instruments use data collection in the form of observations and in-depth interviews. Four hypotheses were developed to explain the influence between causal relationships through hypothesis testing and analyzed using Structural Equation Modeling with the help of LISREL 8.8 software. The analysis results of this study showed that through a smooth-moving value approach, there was a significant favorable influence of behavioral anomalies on the poverty rate. The study concluded that this movement of subtle values could be an attemptto raise awareness and change in the emergence of behavioral anomalies of people in disadvantaged areas. Thisstudy contributes to the understanding that the value of smooth-moving behaviorcan be an attempt to improve the emergence of societal behavioral anomalies. This ingenious solution can strengthen values, attitudes, mental and moral systems to reduce poverty in disadvantaged areas.
\end{abstract}

Keywords: fine moving value, behavioral a nomalies, poverty, disadvantaged areas

JEL Codes: I31, I32

\section{Introduction}

Indonesia is a wealthy country with resources, be they human resources or natural resources. Therefore, all activities are planned and carried out taking into account the needs of future generations, conserving biodiversity, taking a sustainable approach to the use of natural resources, the restoration and consolidation of spatial order, as well as the protection requirements of naturally valuable areas (Sobczak et al., 2021). However, all the natural wealth contained therein is regulated by the state. Therefore, the divestment of significant natural resources can be used to maintain the boundaries of external influence (Peri Herzovich \& Govrin, 2021).

The source of wealth is used for the welfare and prosperity of the people. The influence of global resources and environmental challenges can drive significant behavioral change (Malik et al., 2020). Explanations of behaviors that encourage more considerable differences are likely to represent a lower risk (Rangel et al., 2020). While reducing competitive positions, one can take advantage of the innovation

\footnotetext{
+ Corresponding author. Tel.: +6282230101105; address: Mastrip street 164, Jember, East Java, Indonesia, cod 68121

Email address: andarula.galushasti@gmail.com; andarula@polije.ac.id
} 
processes, productivity, shared measurable success, new mental, environmental conditions, and long-term prosperity. It provides a unique approach to solving inherent problems (Clauss et al., 2020). Prosperity can be felt by people and will have the impact so that poverty can be overcome. Therefore, poverty reduction is an important goal to capture affluent living standards (N. Lee \& Rodríguez-Pose, 2021).

Although Indonesia is a resource-rich country, it continues to work to solve poverty for its citizens. However, poverty negatively impacts health, including malnutrition, lack of healthcare access, limited resource management, increased conflict and violence, and cognitive behavior (Batelaan, 2021). This impact is due to the lack of universal solutions that can alleviate poverty.

Poverty triggers a behavioral anomaly in society. Several recent studies have empirically proven that it contradicts its principles, leading to so-called behavioral irregularities (González Fernández \& Cruz Rambaud, 2018). Many conditions, such as those in low-income households, lower their thermal expectations due to fuel poverty, creating strange comfort behaviors (Malik et al., 2020). The presence of behavioral anomalies indicates that individual learning is not just to avoid a deviation of behavior. They recognize their own mistakes and the negative consequences of wrong behavior (Kirchgässner, 2017). One way to approach problems with such behavior is to study the neural and brain correlation variations of empathy and theory of mind in an experimental paradigm, using behavioral control approaches or self-reports (Melloni et al., 2020). In addition, in terms of financial economics, a macro dimension describes the anomaly of the market hypothesis that the behavioral model can explain. In contrast, the micro extent of economic behavior analysis deviations in individual behavior (Neshenko et al., 2021).

Deviations in the value of behavior and morals of the community occur in disadvantaged areas. When people with low moral standards settle in a room, their reputation deteriorates. It will result in less attractiveness, and self-worth will gradually decrease (Kisiala \& Rącka, 2021). It should be supported in order to build sustainability and stability by integrating the principles of good governance and providing definite values with the moral principles of society (Kurniawan \& Galushasti, 2021). Such communities that live in disadvantaged areas tend to be poorer in various dimensions, such as unequal access to quality education, decent-paying jobs, affordable housing, safe neighbors, quality food, and health services (Duque, 2021). Gaussian Process Subset Scanning (GPSS) detects community behavioral anomalies that correspond to significant public health events (Neill \& Herlands, 2018). In addition, maintaining low levels of investment in infrastructure in the poorest areas can perpetuate regional inequality and poverty levels in the country (Medeiros et al., 2021).

Therefore, research requires a good approach. The expanded system is reflected in the behavioral equation step (De Caigny et al., 2020). It is a concern to move towards practices in society. The information leaves no one behind, builds resilience, and has deep-rooted sustainable development goals in community development (Ullah et al., 2021). There is a behavioral activity in a standardized test that fails to detect differences between community activities. Perhaps that activity suggests that it is likely that this approach is unrelated or that this behavioral approach is not a sensitive enough technique in a specific context (Di Giminiani et al., 2017). The formation of behavioral values of independence, courage, creativity, responsibility, honesty, patience, and making an example with a subtle approach or movement. The effectiveness of relevant matters and behaviors must be studied through the right behavioral strategies expected to influence effective societal behavior (Kurniawan \& Galushasti, 2021).

Value is a concept that resides in the human mind that is hidden, not in an empirical world. A value is a standard of behavior, a measure that determines a criterion so that that standard will color a person's behavior. Values for a person are not static, but they are constantly changing. Everyone would think something was good according to his or her view at the time. Therefore, the value system that a person has can be built and directed. Thus, a person's attitude is highly dependent on the value system that is considered the most correct, 
and then that attitude will control the person's behavior. The cultivation of values starts from teaching the proper knowledge of the value, then providing a good example and getting used to doing the right and appropriate things, and allows analyzing problem situations to add insight in order to be able to weigh certain attitudes and encourage them to formulate their actions that suit their choices.

A person's commitment to a particular value occurs through the formation of attitude or mental, which is a person's tendency towards an object. If a person is confronted with an object, he will show symptoms of displeasure or dislike. A person's statement of pleasure and displeasure with the object he or she is facing will be significantly influenced by his level of understanding of the object. Therefore, the level of reasoning towards an object and the ability to act on it will determine a person's attitude towards the object in question. The formation of attitudes can be done through the example of giving advice, the process of assimilation, or exemplifying and ordering.

Fine moving value is an approach to slowly and profoundly influencing individuals or organizations' values and attitudes in a particular living environment. Three indicators can affect fine-moving value: wild thinking strategies, behavioral value systems, and transparency (Kurniawan \& Galushasti, 2021).

There is a solid need to resolve poverty to avoid people's values and behavior (Sikandar et al., 2021). This approach with the movement of subtle values can be an effort to improve the anomaly of community behavior and be a real solution in minimizing poverty levels in disadvantaged areas.

\section{Research Elaborations}

This study is included in quantitative research with regional populations in Indonesia designated as lagging regions in 2020-2021. Disadvantaged areas are districts whose regions and communities are less developed compared to other regions on a national scale. An area is defined as based on criteria such as community economy, human resources, facilities and infrastructure, regional financial capabilities, accessibility, and characteristics of the area. In Indonesia, the president can establish new disadvantaged areas based on the establishment, expansion, and incorporation of district areas; or attempts to resolve extraordinary circumstances, circumstances of conflict, or natural disasters.

The sampling method uses a non-probability sampling method with purposive sampling type, namely in sampling by determining representative criteria, taking and recording a small portion of the actual or other examples, only using approximate characteristic values. The sample of respondents was chosen by 110 people divided by 11 people each from each region in 10 provinces designated as lagging areas. The primary data collection was conducted through observations and in-depth interviews with the Head of the Community and Village Empowerment Office. Secondary data was obtained with supporting documentation, manuscripts, and literature studies. Four hypotheses have been developed to explain the influence of causal relationships through hypothesis testing. A data analysis used in this study is Structural Equation Modeling (SEM) with the help of LISREL 8.8 software.

\section{Results and Discussion}

The validity and reliability test in the SEM model in the LISREL program can be done using the CFA confirmatory factor analysis measurement model, which will provide results in path diagrams. Analysis of the validity of the measurement model is done by examining whether the t-value of the variable observed in the model qualifies well, i.e., more significant than the critical value $>1.96$; and standardized loading factors of the observed variables in the model have qualified well, namely $>0.70$. 
Reliability analysis of measurement models is done by calculating construct reliability (CR) and variance extracted (VE) values from standardized loading factors and error variance. The requirement of a good Construct Reliability (CR) value is $>0.70$, but if the CR value is in the range of 0.60 and 0.70 , then reliability still falls into the excellent category. Thus, Nilai VE $>0.50$ is a good measure of reliability. However, this measure is usually an option in research, which can be used or not used in the study, but it would be better if included.

Table 1: Test Validity and Reliability - $2^{\text {nd }} C F A$

\begin{tabular}{|cllllll|}
\hline Variable & \multicolumn{2}{l}{ Validity } & & & Reliability & Information \\
\cline { 2 - 6 } & SLF & t-value & Error & CR & VE & \\
\hline $\mathbf{X}_{\mathbf{1}}$ & 0.89 & $* *$ & & 0.87 & 0.69 & Good \\
$\mathbf{X}_{\mathbf{2}}$ & 0.80 & 7.22 & 0.15 & & & Good \\
$\mathbf{X}_{\mathbf{3}}$ & 0.58 & 5.64 & 0.52 & & & Good \\
\hline & & & & 0.88 & 0.63 & Good \\
$\mathbf{Z}_{\mathbf{1}}$ & 0.83 & $* *$ & 0.25 & & & Good \\
$\mathbf{Z}_{\mathbf{2}}$ & 0.66 & 6.56 & 0.43 & & & Good \\
$\mathbf{Z}_{\mathbf{3}}$ & 0.83 & 8.38 & 0.25 & & & Good \\
$\mathbf{Z}_{\mathbf{4}}$ & 0.51 & 4.93 & 0.43 & & & Good \\
\hline & & & & 0.91 & 0.66 & Good \\
$\mathbf{Y}_{\mathbf{1}}$ & 0.37 & $* *$ & 0.39 & & & Good \\
$\mathbf{Y}_{\mathbf{2}}$ & 0.67 & 3.30 & 0.29 & & & Good \\
$\mathbf{Y}_{\mathbf{3}}$ & 0.90 & 3.46 & 0.14 & & & Good \\
$\mathbf{Y}_{\mathbf{4}}$ & 0.67 & 3.27 & 0.32 & & & Good \\
$\mathbf{Y}_{\mathbf{5}}$ & 0.75 & 3.37 & 0.25 & & & Good \\
$\mathbf{Y}_{\mathbf{6}}$ & 0.86 & 3.54 & 0.37 & & & \\
\hline
\end{tabular}

$* *=$ Default, $\mathrm{t}$-value value not estimated

(Source: Author based on data from LISREL 8.8)

Test results of validity and reliability measurement model Confirmatory Factor Analysis ( $\left.2^{\text {nd }} \mathrm{CFA}\right)$ shows that the entire variable is valid and reliable and meets all test requirements well.

Table 2: Goodness of Fit - $2^{\text {nd }}$ CFA

\begin{tabular}{|c|l|l|c|}
\hline GOF Size & \multicolumn{1}{|c|}{ Target-Match Rate } & \multicolumn{1}{c|}{ Estimated Results } & Level \\
\hline Chi-Square $P$ & Small value $(\mathrm{p}>0.05)$ & $\chi^{2}=57.79(\mathrm{p}=0.147)$ & Good \\
\hline NCP - Interval & Small value-Narrow intervals & $10,79(0.0 ; 34.34)$ & Good \\
\hline RMSEA - P $($ close fit $)$ & RMSEA $\leq 0.05(\mathrm{p} \geq 0.05)$ & $0.046(\mathrm{p}=0.66)$ & Close \\
\hline ECVI & A small value close to ECVI S* & $\mathrm{M}^{*}=1.22 ; \mathrm{S}^{*}=1.55 ; \mathrm{I}^{*}=9.34$ & Good \\
\hline AIC & A small value close to AIC $\mathrm{S}^{*}$ & $\mathrm{M}^{*}=119.81 ; \mathrm{S}^{*}=156.12 ; \mathrm{I}^{*}=1005.39$ & Good \\
\hline CAIC & A small value close to CAIC S* & $\mathrm{M}^{*}=234.62 ; \mathrm{S}^{*}=444.76 ; \mathrm{I}^{*}=1049.80$ & Good \\
\hline NFI & NFI $\geq 0.90$ & 0.95 & Good \\
\hline NNFI & NNFI $\geq 0.90$ & 0.98 & Good \\
\hline CFI & CFI $\geq 0.90$ & 0.97 & Good \\
\hline IFI & IFI $\geq 0.90$ & 0.98 & Good \\
\hline RFI & RFI $\geq 0.90$ & 0.93 & Good \\
\hline CN & CN $\geq 200$ & 130.26 & Bad \\
\hline
\end{tabular}




\begin{tabular}{|c|l|l|c|}
\hline RMR & Standardized $\quad$ RMR $\leq 0.05$ & 0.030 & Good \\
\hline GFI & GFI $\geq 0.90$ & 0.94 & Good \\
\hline AGFI & AGFI $\geq 0.90$ & 0.92 & Marginal \\
\hline
\end{tabular}

* M= Model; $\mathrm{S}=$ Saturated; I=Independent

(Source: Author based on data from LISREL 8.8)

The Goodness of Fit - $2^{\text {nd }}$ CFA test shows that a size GOF offers a lousy fit and other sizes show an excellent fit match, so it can be concluded that the model's overall fit is a good fit.

Table 3: Hypothesis Testing Criteria - Evaluation of Structural Model Coefficients

\begin{tabular}{|l|l|l|l|}
\hline Hypothesis & Estimation & t-value & Conclusion \\
\hline Behavioral anomalies positively affect fine moving values & 0,41 & 3,49 & Supported \\
\hline Subtle values positively affect poverty rates & 0,63 & 3,07 & Supported \\
\hline $\begin{array}{l}\text { Subtle moving values can mediate the real influence of } \\
\text { behavioral anomalies on poverty levels. }\end{array}$ & & Supported \\
\hline $\begin{array}{l}\text { The whole mediation effect has been appropriate: the weight of behavioral anomalies } \\
\text { regression to poverty levels becomes insignificant when mediation performance is inserted. }\end{array}$ & \\
\hline P1: BA $\rightarrow$ P & 0,50 & 2,55 & Supported \\
\hline P2: BA $\rightarrow$ FMV & 0,42 & 3,51 & Supported \\
\hline P3: FMV $\rightarrow$ P & 0,73 & 3,11 & Supported \\
\hline P4: BA $\rightarrow$ P & 0,22 & 1,89 & Unsupported \\
\hline
\end{tabular}

(Source: Author based on data from LISREL 8.8)

GOF model testing resulted in a good reception model, with a significance level of chi-square $=0.147$; RMSEA (0.046), GFI (0.94), NFI (0.95), CFI (0.97), RMR (0.030). All testing criteria are above the limit value that indicates acceptance of the research model to an ideal level. Mediation effect testing showed the $\mathrm{t}$-value critical value for all hypotheses to be above 1.96, which indicates a full mediation effect. Therefore, all hypotheses proposed in this study are well received.

Based on the research results, a good approach is needed to improve behavioral and moral values. This approach happens because the matter is a concept or standard of behavior that reflects the hidden human mind. As a means of measuring in determining a criterion, the idea will color behavior in society. These studies show that the cultivation of behavioral values starts from teaching the proper knowledge of the matter. They are then providing good examples, getting used to doing the right and appropriate things, and providing an opportunity to analyze problem situations. Finally, to add insight and ability to weigh certain behaviors with their values, and encourage them to formulate actions that must be done according to their choice. This motivation influences complex behaviors in the logic used for decision-making (de la Cruz et al., 2018).

Some studies state that behavioral impulses have previously been shown to be effectively applied, and self-monitoring is an essential component of changing behavior for the better (Borg et al., 2020). His transformation of the so-called soul is how people behave and judge the soul based on the behavior shown (Farrall et al., 2021).

The formation of behavioral values of independence, courage, creativity, responsibility, honesty, patience, make an example with a subtle approach or movement. That subtle moving approach can be seen in our daily lives, namely the mother's behavior or actions in educating her child. Therefore, applying a model 
of example in children in the family looks very effective to improve the ability, support the child's talent and creativity to be higher and more developed, and create anticipation in the deviation of values and behaviors that are feared to occur.

Several studies also support that behaviors with some purpose for uniqueness in meeting needs will be a behavioral representation of their state of mind (Jiang et al., 2021). High authoritative levels will impact more elevated levels of emotion regulation and lower levels of behavioral problems. (Haslam et al., 2020). Personal values affect the level of satisfaction and outcomes of student behavior (Kumar, 2018). The value of behavioral beliefs, when attitudes toward perceived values increase through friendly environmental behavior, the value of behavioral ideas leads to increased behavioral intentions (M. T. Lee et al., 2020).

Determinants of intention, attitude toward behavior, social norms or social pressures, and perceived behavioral control all increase when aware of environmental issues, increasing their intention to take actions that support the environment. (M. T. Lee et al., 2020). Thus, this approach with the movement of subtle values can be an effort to improve the anomaly of community behavior and become a real solution in minimizing poverty in disadvantaged areas.

\section{Conclusions}

Based on the results and discussions above, the movement of subtle values proved to be an influential variable to trigger the emergence of behavioral anomalies in society. The logic of this path is the first step and means of demonstrating the effectiveness of behaving rationally. Fine moving value capabilities can answer research gaps by showing that the movement of values is smooth as a strategic input. Approaches with subtle values can strengthen value systems, attitudes, mental and moral efforts to reduce poverty in disadvantaged areas.

The findings of this study make a real contribution to understanding the value of fine moving behavior which can be an ingenious way to strengthen the study of the formation of values, attitudes, mental and moral systems as capital in the recovery of poverty in areas scattered in Indonesia, and can be separated from criteria in areas designated as disadvantaged areas. The evidence is in the significant reduction of areas that were previously designated as disadvantaged areas.

Based on the conclusions of the above research, it can be shown that the successful application of this concept of finely moving value is focused on one of the countries that belong to developing countries, namely Indonesia. Therefore, the application of this concept needs to be studied further in future research, in a followup study related to compatibility or successful application of the concept of fine moving value in countries where there is still an unresolved phenomenon of poverty.

\section{Acknowledgments}

The author thanks the Director, Head of Research and Community Service Institute, Chairman of agribusiness Management Department, all the academic community of State Polytechnic of Jember, Master Trainer, and the entire Scopus Home Trainer Team for all support and assistance in this research.

\section{References}

[1] Batelaan, K. (2021). 'When whites catch a cold, bla ck folks get pneumonia': a look at racialized poverty, space and HIV/AIDS. Social Identities, 27(2), 262-282. https://doi.org/10.1080/13504630.2020.1823827

[2] Borg, S., Öberg, B., Nilsson, L., Söderlund, A., \& Bäck, M. (2020). The added value of a behavioral medicine 
intervention in phy siotherapy on adherence and physical fitness in exercise-based cardiac rehabilitation (ECRA): A randomised, controlled trial. Patient Preference and Adherence, 14, $2517-2529$. https://doi.org/10.2147/PPA.S285905

[3] Clauss, T., Kraus, S., Kallinger, F. L., Bican, P. M., Brem, A., \& Kailer, N. (2020). Orga nizational a mbidexterity and competitive advantage: The role of strategic agility in the exploration-exploitation paradox. Joumal of Innovation and Knowledge, xx xx. https://doi.org/10.1016/j.jik.2020.07.003

[4] De Caigny, A., Coussement, K., \& De Bock, K. W. (2020). Leveraging fine-grained transaction data for customer life event predictions. Decision Support Systems, 130(May 2019), 113232. https://doi.org/10.1016/j.dss.2019.113232

[5] de la Cruz, M. E., Verdú Jover, A. J., \& Gómez Gras, J. M.(2018). Influence of the entrepreneur's social identity on business performance through effectuation. European Research on Management and Business Economics, 24(2), 90-96.https://doi.org/10.1016/j.iedeen.2017.11.003

[6] Di Giminiani, P., Na sira hmadi, A., Malcolm, E. M., Leach, M. C., \& Edwards, S. A. (2017). Docking piglet tails: How much does it hurt and for how long? Physiology and Behavior, 182(July), 69-76. https://doi.org/10.1016/j.physbeh.2017.09.028

[7] Duque, R. B. (2021). Black Health Matters Too... Especially in the Era of Covid-19: How Poverty and Race Converge to Reduce Access to Quality Housing, Safe Neighborhoods, and Health and Wellness Services and Increase the Risk of Co-morbidities Associated with Global Pandemics. Journal of Racial and Ethnic Health Disparities, 8(4), 1012-1025. https://doi.org/10.1007/s40615-020-00857-w

[8] Farrall, S., Hay, C., Gray, E., \& Jones, P. M. (2021). Behavioural Thatcherism and Nostalgia: tracing the everyday consequences of holding Thatcherite values. British Politics, 16(3), 272-294. https://doi.org/10.1057/s41293-01900130-7

[9] Gonzá lez Fernández, I., \& Cruz Ra mbaud, S. (2018). Inconsistency in intertemporal choice: a behavioral approach. European Journal of Management and Business Economics, 27(3), 231-248. https://doi.org/10.1108/EJMBE-012018-0012

[10]Ha slam, D., Poniman, C., Filus, A., Sumargi, A., \& Boediman, L. (2020). Parenting Style, Child Emotion Regulation and Behavioral Problems: The Moderating Role of Cultural Values in Australia and Indonesia. Marriage \& Family Review, 56(4), 320-342.https://doi.org/10.1080/01494929.2020.1712573

[11]Jiang, X., Kim, A., Kim, K. A., Yang, Q., García-Fernández, J., \& Zhang, J. J. (2021). Motivational Antecedents, Value Co-Creation Process, and Behavioral Consequences in Participatory Sport Tourism. Sustainability, 13(17), 9916. https://doi.org/10.3390/su13179916

[12]Kirchgä ssner, G. (2017). Soft paternalism, merit goods, and normative individualism. European Journal of Law and Economics, 43(1), 125-152. https://doi.org/10.1007/s10657-015-9500-5

[13]Kisiala, W., \& Rącka, I. (2021). Spatial and statistical a nalysis of urban poverty for sustainable city development. Sustainability (Switzerland), 13(2), 1-18. https://doi.org/10.3390/su13020858

[14]Kumar, S. (2018). Individual personal values as mediators during behavioral perception and transference. Interpersona: An International Journal on Personal Relationships, 12(1), $122-132$. https://doi.org/10.5964/ijpr.v12i1.221

[15]Kurniawan, B. P. Y., \& Galushasti, A. (2021). Effectiveness of fine-moving value in developing theoretical model of organizational performance: A perspective of the theory of planned behavior. Academy of Strategic Management Journal, 20(3), 1-13. https://www.abacademies.org/articles/Effectiveness-of-fine-moving-value-in-developingtheoretical-model-of-organizational-performance-a-perspective-of-the-theory-of-planned-behavior-1939-6104-203-749.pdf 
[16]Lee, M. T., Liu, J. M., \& Bora zon,E. Q. (2020). Evaluating the effect of perceived value of ecosy stem services on tourists' behavioral intentions for Aogu Coastal Wetland. Sustainability (Switzerland), 12(15). https://doi.org/10.3390/su12156214

[17]Lee, N., \& Rodríguez-Pose, A. (2021). Entrepreneurship and the fight against poverty in US cities. Environment and Planning A, 53(1), 31-52. https://doi.org/10.1177/0308518X20924422

[18]Ma lik, J., Bardhan, R., Hong, T., \& Piette, M. A. (2020). Contextualising a daptive comfort behaviour within lowincome housing of Mumbai, India. Building and Environment, 177(April), 106877. https://doi.org/10.1016/j.buildenv.2020.106877

[19]Medeiros, V., Ribeiro, R. S. M., \& Amaral, P. V. M. do.(2021). Infrastructure and household poverty in Brazil: A regional approach using multilevel models. World Development, 137, 105118. https://doi.org/10.1016/j.worlddev.2020.105118

[20]Melloni, E., Benedetti, F., Vai, B., \& Lalumera, E. (2020). Not understanding others. The rdoc a pproach to theory of mind and empathy deficits in schizophrenia, borderline personality disorder and mood disorders. Phenomenology and Mind, 18, 162-181.https://doi.org/10.17454/pam-1813

[21]Neill, D. B., \& Herlands, W. (2018). Machine Learning for Drug Overdose Surveillance. Journal of Technology in Human Services, 36(1), 8-14. https://doi.org/10.1080/15228835.2017.1416511

[22]Neshenko, N., Bou-Harb, E., \& Furht, B. (2021). A beha vioral-based forensic investigation a pproach for a nalyzing attacks on water plants using GANs. Forensic Science International: Digital Investigation, 37, 301198. https://doi.org/10.1016/j.fsidi.2021.301198

[23]Peri Herzovich, Y., \& Govrin, A. (2021). Psychoanalysis and Interdisciplinarity With Non-analytic Psychotherapeutic Approaches Through the Lens of Dialectics. Frontiers in Psychology, 12(July), 1-13. https://doi.org/10.3389/fpsyg.2021.697506

[24]Rangel, M. A., Nobles, J., \& Hamoudi, A. (2020). Brazil's Missing Infants: Zika Risk Changes Reproductive Beha vior. Demography, 57(5), 1647-1680. https://doi.org/10.1007/s13524-020-00900-9

[25]Sikandar, F., Erokhin, V., Shu, W. H., Rehman, S., \& Ivolga, A. (2021). The impact of foreign capital inflows on agriculture development and poverty reduction: Panel data analysis for developing countries. Sustainability (Switzerland), 13(6). https://doi.org/10.3390/su13063242

[26]Sobczak, E., Bartniczak, B., \& Raszkowski, A. (2021). Implementation of the No Poverty Sustainable Development Goal(SDG) in Visegrad Group (V4). Sustainability, 13(1030), 1-21.https://doi.org/10.3390/su13031030

[27]Ullah, A., Kui, Z., Ullah, S., Pinglu, C., \& Khan, S. (2021). Sustainable utilization of financial and institutional resources in reducing income inequality and poverty. Sustainability (Switzerland), 13(3), 1-25. https://doi.org/10.3390/su13031038

Manuscript submitted: 24.09.2021

Manuscript received in revisedform: 14.10 .2021

Manuscript accepted: 15.10 .2021 